\title{
A realização do objeto indireto anafórico de terceira pessoa na variedade do português europeu falado no Funchal (Ilha da Madeira)
}

\author{
The realization of the anaphoric third person OI in an urban European Portuguese \\ spoken variety (Funchal, Madeira Island)
}

\author{
Aline Maria Bazenga \\ Universidade da Madeira/CLUL \\ Madeira, Portugal
}

\begin{abstract}
Resumo: A investigação que tem vindo a ser realizada desde 2010 sobre a variação sintática nas variedades do português falado na Ilha da Madeira (Portugal) confirma a sua especificidade no conjunto de variedades geográficas do Português Europeu (PE) e a sua integração, com base em critérios lexicais e fonéticos, num dos três grupos principais e autónomos dos dialetos portugueses, o grupo dos dialetos insulares. Dando continuidade ao estudo sobre a sintaxe madeirense, este trabalho procura investigar as estratégias de realização do objeto indireto (OI) anafórico de terceira pessoa numa variedade insular do PE, a variedade falada no Funchal, na Ilha da Madeira. A metodologia adotada tem por base os pressupostos teórico-metodológicos da sociolinguística quantitativa de base laboviana, aplicados a uma amostra estratificada de entrevistas realizadas junto de 12 informantes madeirenses, residentes no Funchal, capital da ilha da Madeira, selecionada a partir do Corpus Sociolinguístico do Funchal. A análise terá em conta a literatura de referência e será conduzida no sentido de procurar saber quais os fatores linguísticos e extralinguísticos que atuam na variação das formas de expressão da função OI, nomeadamente as seguintes (i) com clítico lhe (s) $e$ (ii) com SP (preposição $a$ e para), unicamente com pronome forte ele(s) e ela(s). Os resultados apontam para a ocorrência dos dois tipos de variantes, quantitativamente diferenciados. Com efeito, não só se atesta o uso da construção com a preposição para, normalmente excluída dos dados do PE, como também a pouca frequência do clítico lhe, tida como variante padrão do PE.
\end{abstract}

Palavras-chave: Objeto indireto (OI) anafórico de $3^{\mathrm{a}}$ pessoa (singular/plural). Clítico dativo lhe(s). SP com a/para + pronome tónico ele(s), ela(s). Variedade insular e urbana do PE (Funchal). Sociolinguística variacionista.

\begin{abstract}
The research that has been carried out since 2010 on the syntactic variation in the varieties of spoken Portuguese in the Island of Madeira (Portugal) has confirmed its specificity in the set of European Portuguese (EP) geographic varieties and its integration, based on lexical and phonetic criteria, as one of the three main and autonomous groups of the Portuguese dialects, the group of island dialects. Continuing the study on Madeiran syntax, this work aims to investigate strategies for the realization of the third person anaphoric indirect object (OI) in an insular variety of EP, the spoken variety in Funchal, Madeira Island. The methodology adopted is based on the theoretical-methodological assumptions of the Labovian-based quantitative sociolinguistics, applied to a stratified sample of interviews carried out with 12 Madeiran informants residing in the capital and selected from the Sociolinguistic Corpus of Funchal. The analysis will take into account the literature and will be carried out to uncover the linguistic and extralinguistic factors that act in the variation of the forms of expression of the OI function, namely the following ones (i) the Dative clitic lhe(s) (ii) SP (preposition $a$ and para), followed by a strong pronoun ele(s) and ela(s).The results point to the occurrence of the two considered types of variants but quantitatively differentiated. In fact, not only is the use of SP with para is observed, which is normally excluded from the standard PE data, but also the infrequent occurrence of the standard variant in PE with clitics lhe $(s)$.
\end{abstract}

Keywords: Anaphoric indirect objet (IO) of 3th person (singular/plural). Dative clitics lhe (s). SP with prepositions a/para + strong pronoun ele(s), ela(s). Insular and urban variety of EP (Funchal). Variationist Sociolinguistics.

\section{*Professora Doutora - Universidade da Madeira, Ilha da Madeira, Portugal. E-mail:} aline.bazenga@staff.uma.pt. 


\section{INTRODUÇÃO}

A literatura publicada sobre as propriedades sintáticas e semânticas do constituinte frásico com função OI tem apontado para o contraste existente entre as variedades padrão do PE e do PB (BRITO, 2009, 2014; BERLINCK, 1996; TORRES MORAIS; BERLINCK, 2006, 2007; TORRES MORAIS; SALLES, 2010; FREIRE, 2005, 2011). No $\mathrm{PB}$, o clítico dativo lhe/ thes de $3^{\mathrm{a}}$ pessoa para a realização de OI anafórico está em desuso crescente, preferindo os falantes desta variedade o recurso a SP, introduzido pelas preposições a e para, seguindo de SN ou de pronome forte $(e l e(s)$, ela $(s))$. Inversamente, na variedade padrão do $\mathrm{PE}$, a escolha dos falantes recai sobre o clítico, estando a construção $\mathrm{SP}$ restrita à preposição a seguida de SN. Nesta variedade, como afirmam Gonçalves e Raposo (2013, p. 1172), “o complemento indireto não pode ser realizado por um sintagma preposicional consistindo na sequência $a+$ pronome forte pessoal". Na modalidade falada, estes contrastes podem ser ilustrados pelos seguintes exemplos:

(1) a. O Miguel mostrou as fotografias à mãe $(\sqrt{ } \mathrm{PE} / \sqrt{ } \mathrm{PB})$

b. O Miguel mostrou as fotografias a ela $(* \mathrm{PE} / \sqrt{\mathrm{PB}})$

c. O Miguel mostrou as fotografias para ela $(* \mathrm{PE} / \sqrt{\mathrm{PB}})$

d. O Miguel mostrou-lhe as fotografias $(\sqrt{ } \mathrm{PE} / \mathrm{PPB})$

e. O Miguel mostrou-lhe as fotografias, a ela $(\sqrt{ } \mathrm{PE} / \mathrm{PPB})$

Como tem vindo a ser observado noutros domínios da gramática, algumas particularidades sintáticas do português falado do Funchal - uma variedade insular e urbana do PE - não são observadas nas variedades continentais do PE. Paralelamente, alguns destes fenómenos eram atribuídos exclusivamente às variedades do $\mathrm{PB}$, como, por exemplo, a alternância ter / haver em construções existenciais (BAZENGA, 2018). O recente desenvolvimento da investigação sobre variação sintática em variedades dialetais do PE, e da variedade madeirense em particular, conduziu a um aprofundar da reflexão sobre as relações entre variedades do português. Com base em investigação empírica já realizada, Bazenga (no prelo) considera a hipótese de um continuum entre as duas variedades nacionais (PE e PB) e não o seu distanciamento. Neste continuum, a variedade insular do PE ocuparia uma posição de fronteira, tornando possível um alinhamento de variedades, na esteira da hipótese da deriva secular defendida por Naro e Scherre (2007), segundo a qual o português brasileiro seria uma espécie de continuação do português arcaico ${ }^{1}$.

Com este trabalho, pretende-se contribuir para o aprofundar da hipótese sumariamente acima referida, através de uma análise preliminar do comportamento dos falantes de uma variedade urbana e insular (Funchal, capital da ilha da Madeira) relativamente à realização anafórica da função OI de terceira pessoa do singular e do plural (3PS e 3PP, respetivamente). Para além da realização padrão com clítico, a análise terá por foco outras possibilidades: a construção SP com as preposições a e para, seguidas de

${ }^{1}$ Sobre a apresentação desta hipótese e de outras relativas às origens do PB, ver Lins (2009). 
pronome forte, ilustradas em (1b) e (1c), sujeitas a fortes restrições no PE padrão e muito frequentes, pelo contrário, em variedades do $\mathrm{PB}$.

$\mathrm{O}$ artigo está divido em três secções. Após uma breve apresentação da função OI (secção 2) e da metodologia (secção 3), e a anteceder as considerações finais, serão analisados os dados empíricos produzidos por falantes madeirenses da cidade do Funchal (secção 4).

\section{A FUNÇÃO OI}

A função OI é marcadamente complexa. A sua complexidade está relacionada, entre outros aspetos, com a sua não-homogeneidade estrutural, como salienta Brito (2009, p. 142). Não só existem dativos dependentes de verbos pertencentes a diferentes classes semânticas, com três argumentos, como em (2) e (3), e com dois, como em (4), como também o constituinte OI pode assumir diferentes interpretações semânticas, nomeadamente as de beneficiário, destinatário e origem:

(2) Verbos transitivos de 3 lugares; verbos de transferência / mudança de posse

a. O Pedro deu/entregou/vendeu o livro ao António [destinatário]

b. O Pedro roubou/tirou/comprou o livro ao António. [origem]

c. O Pedro construiu uma casa aos pais [beneficiário]

(3) Verbos transitivos de 3 lugares; verbos diretivos

a. O Professor ordenou ao aluno que saísse da sala. [destinatário]

(4) Verbos transitivos de 2 lugares

Psicológicos: a. O concerto agradou ao público. [destinatário]

Posse: b. Este livro pertence ao professor [destinatário]

(GONÇALVES; RAPOSO, 2013, p. 1171-1180)

Em certos contextos, OI pode ainda corresponder à realização de um argumento [- animado]. Tal ocorre, por exemplo, com predicadores de dois lugares (obedecer ao regulamento, sobreviver ao massacre), ou ainda com dar ou fazer, seguidos de um OD cujo núcleo é um nome deverbal. Com estes predicadores é ainda possível uma construção onde OI passa a ter função de OBLI, como ilustrado em (5):

(5) a. A Maria deu [uma pintura $]_{\mathrm{OD}}[\text { às estantes }]_{\mathrm{OI}}$

a'. A Maria deu [uma pintura] $\mathrm{OD}$ [nas estantes] ${ }_{\mathrm{OBL}}$

b. Eles fižram [uma enorme limpeza] OD [à casa]

b'. Eles fizeram [uma enorme limpeza $]_{\mathrm{OD}}[n a \text { casa }]_{\mathrm{OBL}}$

(MATEUS et al.,1983, p. 289)

No que se refere à realização pronominal de OI, o sistema do PE dispõe dos clíticos do caso dativo, $3 \mathrm{PS}$ e $3 \mathrm{PP}$, lhe/ lhes, respetivamente. Estes clíticos não substituem todos 


\section{das Letras}

os SP introduzidos por $a$; apenas podem realizar um constituinte [ + animado] e com a função OI, como indicado em (6):

(6) a. O João deu (à Maria) um livro (à Maria).

a'. O João deu-lhe um livro.

(GONÇALVES, 2016, p. 102)

b. Eles assistiram ao espetáculo.

b'. *Eles assistiram-lhe.

(GONÇALVES, 2016, p. 104)

Para além destas propriedades, the e thes podem ser combinados com clíticos o(s), $a(s)$ com função OD, produzindo amálgamas pronominais, ou formas contraídas, como lho(s), lha(s). O sistema pronominal padrão em PE é, assim, marcado por um grau elevado de complexidade, não só em termos de número de constituintes (Quadro 1) como também no que se refere a regras de uso.

Quadro 1: Pronomes pessoais do PE (clíticos e não clíticos) (MARTINS, 2013, p. 2233)

\begin{tabular}{|c|c|c|c|c|c|c|}
\hline & \multicolumn{5}{|c|}{ FORMAS ÁTONAS (Clíticas) } & \multirow{2}{*}{\begin{tabular}{|c|}
$\begin{array}{l}\text { FORMAS } \\
\text { TÓNICAS }\end{array}$ \\
$\begin{array}{c}\text { Oblíquo } \\
\text { /Dativo }\end{array}$
\end{tabular}} \\
\hline & Acusativo & Dativo & Nominativo & Nominativo & Acusativo & \\
\hline & $\begin{array}{l}\text { (Compl. } \\
\text { Direto) }\end{array}$ & $\begin{array}{l}\text { (Compl. } \\
\text { Indireto) }\end{array}$ & (Sujeito) & (Sujeito) & $\begin{array}{l}\text { (Compl. } \\
\text { Direto) }\end{array}$ & $\begin{array}{l}\text { Compl. } \\
\text { Preposicio } \\
\text { nado/ } \\
\text { indireto }\end{array}$ \\
\hline $\begin{array}{l}1^{\text {a }} \\
\text { sg. }\end{array}$ & me & me & & $\mathrm{eu}$ & & $\begin{array}{l}\text { mim, } \\
\text { comigo }\end{array}$ \\
\hline $\begin{array}{l}1^{\circ} \\
\text { pl. }\end{array}$ & nos & nos & & nós, a gente & a gente & $\begin{array}{l}\text { nós, } \\
\text { connosco, } \\
\text { a gente }\end{array}$ \\
\hline $\begin{array}{l}2^{\mathrm{a}} \\
\mathrm{sg} .\end{array}$ & te & te & & tu, você & & $\begin{array}{l}\text { ti, contigo, } \\
\text { você, si, } \\
\text { consigo }\end{array}$ \\
\hline
\end{tabular}




\section{das Letras}

\begin{tabular}{|l|l|l|l|l|l|l|}
\hline $\begin{array}{l}2^{\circ} \\
\text { pl. }\end{array}$ & vos & vos & vós, vocês & & $\begin{array}{l}\text { vós, } \\
\text { convosco, } \\
\text { vocês }\end{array}$ \\
\hline $\begin{array}{l}3^{\mathrm{a}} \\
\text { sg. }\end{array}$ & o, a, se & lhe & se (impess.) & ele, ela & & $\begin{array}{l}\text { ele, ela, si, } \\
\text { consigo }\end{array}$ \\
\hline $\begin{array}{c}3^{\mathrm{a}} \\
\text { pl. }\end{array}$ & os, as, se & lhes & & eles, elas & & eles, elas \\
\hline
\end{tabular}

Por outro lado, os dados da aquisição dos pronomes clíticos apontam para o desenvolvimento tardio na sua produção pelas crianças. Este facto resultaria, de acordo com Costa e Lobo (2006, 2007, 2016), da natureza do input, caracterizado pela presença de duas formas de uso em competição - com clítico, por um lado, e a possibilidade de objeto nulo, por outro, conforme os exemplos retirados de Costa e Lobo (2016, p. 432)): tirei a chávena da mesa e pu-la na máquina de lavar vs tirei a chávena da mesa e pus $\varnothing$ na máquina de lavar, respetivamente ${ }^{2}$.

Esta descrição sumária de algumas propriedades relacionadas com a função OI no PE apresenta algumas especificidades quando considerados os dados relativos ao conjunto das variedades do português, brasileiras (PB) ou africanas (PA).

No PB, por exemplo, conforme salientado em Bazenga e Rodrigues (no prelo), paralelamente ao uso de lhe, correspondente à realização do $\mathrm{OI}$, de $3 \mathrm{PS}^{3}$, em queda muito acentuada, observa-se o seu uso produtivo de $2 \mathrm{PS}$, tanto de realização de OI, como em (7b) como de OD (7c).

(7) a. Se o encontrarem, não lhe digam nada ainda. (OI/Dativo - 3PS)

b. Meu filho, vou the contar uma história. (OI/Dativo - 2PS)

c. Eu lhe vi no cinema ontem. (OD/Acusativo - 2PS)

(ALMEIDA, 2016, p. 125)

Os falantes do $\mathrm{PB}$ recorrem ainda a sintagmas preposicionais com pronomes fortes, introduzidos por a, ou por para, como em O José deu o livro a ela / para ela. Em PE, como observado por Gonçalves e Raposo (2013, p. 1171-1180), as duas construções - O João comprou uma casa ao filho / para o filho - não partilham as mesmas propriedades, embora possam ter o mesmo significado básico de beneficiário. No entanto apenas o SP introduzido por a pode redobrar um clítico dativo:

2 O "lhéismo", ou o emprego da forma lhe como OD (NASCENTES, 1960), encontra-se também atestado em dados de aquisição do PE (L1 e L2), conforme os resultados publicados em vários trabalhos de investigação, nomeadamente, em Carmona e Silva (2007), Silva (2009) e Madeira, Crispim e Xavier (2006). ${ }^{3}$ No PB, a realização lhe, de dativo de 3PS, tida como padrão no PE, está quase em desuso na modalidade oral. No entanto o seu uso ainda é atestado na modalidade escrita, como dá conta o trabalho de Freire (2005, 2011), correspondendo, nesta variedade, à estratégia menos utilizada. 
(8) a. O João comprou-lhe uma casa, ao filho.

b. *O João comprou-lhe uma casa, para o filho.

e unicamente o SP introduzido por para pode conter um pronome forte:

(9) a. O João comprou uma casa para ele.

b. *O João comprou uma casa $a$ ele.

Os autores concluem, assim, que, nesta variedade, as duas construções SP com a/para não beneficiam do mesmo estatuto funcional, não podendo ser, assim, consideradas variantes.

Freire (2011) compara as duas variedades (PE e PB), recorrendo a corpora escritos, e os seus resultados apontam para diferenças significativas. A Tabela 1 permite por em evidência o contraste entre as duas variedades no que se refere a este domínio da gramática. No PB, a variante com SP anafórico (seguido de pronome forte mas também de $\mathrm{SN}$ ) corresponde ao uso preferencial (42\%); já no PE, esta construção é a menos frequente $(3 \%)$. O uso de lhe, ainda atestado na modalidade escrita no PB é, no entanto, a estratégia menos utilizada (26\%); inversamente, no PE, constitui a estratégia mais frequente $(83 \%)$.

Tabela 1: Variantes de dativo de 3PS em PB e PE: dados da modalidade escrita (FREIRE, 2011, p. 26)

\begin{tabular}{ccccccc}
\hline & & Lhe & \multicolumn{2}{c}{ SP anafórico } & \multicolumn{2}{c}{ Objeto nulo } \\
\hline PB & $41 / 155$ & $26 \%$ & $65 / 155$ & $42 \%$ & $4 !$ & $32 \%$ \\
\hline PE & $90 / 108$ & $83 \%$ & $3 / 108$ & $3 \%$ & $1 !$ & $14 \%$ \\
\hline
\end{tabular}

As variedades africanas apresentam sincretismos de padrões que se encontram no PE e no PB. Parece desenhar-se, por exemplo, nas variedades do português de Angola e do português de Moçambique uma tendência para o uso de uma única forma, o clítico lhe, tanto para a função OD como para a função OI na 3PS. Já o português falado em São Tomé (PST) apresenta outra configuração. Nesta variedade, como observa Hagemeijer (2016, p. 58),

mais do que o português angolano e o português moçambicano, [o PST] privilegia a ocorrência de pronomes fortes em vez de clíticos, como em "não fico psicologicamente preparado para falar o crioulo forro, respondi ele em nosso português" (PST) (Gonçalves, 2009) [... ] há outras estratégias características que concorrem para a realização dos complementos indiretos, nomeadamente o uso de a ou para (vendi a/para ele). 
O exame sumário dos usos dos clíticos e dos pronomes fortes em variedades geográficas do português fora do espaço europeu restrito (continental) aponta para padrões diferenciados ainda por descrever de maneira aprofundada.

\section{METODOLOGIA}

Estudos anteriores, como o de Bazenga e Rodrigues (no prelo), mostram que a sintaxe pronominal constitui um domínio complexo da gramática, no qual se observa uma variação acentuada em variedades geográficas e sociais do português (L1, L2). A variedade insular do Funchal (Ilha da Madeira) apresenta traços linguísticos singulares, no conjunto das variedades e grupos dialetais do PE, como referido por Brissos, Gillier e Saramago (2016). Uma das especificidades que tem vindo a ser estudada, no domínio da sintaxe, relaciona-se com o sistema pronominal em uso. Com efeito, não só os falantes madeirenses da cidade do Funchal tendem a evitar o uso dos clíticos, como estão atestadas ocorrências não-padrão de the e de ele para marcação de OD anafórico de terceira pessoa (BAZENGA; ANDRADE; RODRIGUES, 2019). Nesta variedade, tal como em algumas variedades africanas, assiste-se a uma regularização dos paradigmas OD (acusativo) e OI (dativo) na terceira pessoa e a sua redução às formas the / lhes, ou seja, a prevalência do fenómeno conhecido como lheísmo, de que se fornece o exemplo retirado do CSF:

(10) é irmã de do homem qu'eu [que eu] tou [estou] agora foi esse atual mo meu namorado _ e e o nessa altura eu não gostava dele nem lheoD podia ver a frente _ (FNC11_MA1)

De modo a verificar a existência ou não de formas de realização de OI com SP ( $a$ / para), uma estratégia considerada não padrão no âmbito do PE, e muito frequente no $\mathrm{PB}$, foram apenas consideradas, nesta análise preliminar, as realizações com clítico (lhe/lhes) e as realizações com SP (a/para) e as correlações destes usos com variáveis extralinguísticas ou sociais (idade, sexo e nível de escolaridade). Não se contemplaram, neste estudo, nem a realização com SP seguida de um SN (à minha mãe/ ao Pedro) nem a realização nula de OI. Um único fator linguístico foi testado: a informação de tipo morfológico (singular / plural) das construções que realizam o OI anafórico.

Para este trabalho, utilizou-se inicialmente uma amostra de 18 entrevistas de informantes do Funchal, selecionadas a partir do Corpus Sociolinguístico do Funchal (CSF) ${ }^{4}$, posteriormente reduzida a 12. A decisão de não incluir as entrevistas dos seis informantes com nível 3 de escolaridade, correspondendo ao Ensino Superior completo, prende-se com o facto de não ter sido observada nenhuma ocorrência da construção não padrão de tipo SP introduzido pela preposição a/para seguida de pronome forte ele/ela/eles/elas.

${ }^{4} \mathrm{O}$ CSF, coordenado por Aline Bazenga (CIERL-UMa e CLUL), é um projeto indexado ao Projeto ARPOFAMA, do CIERL-UMa, a decorrer desde 2014. Dele faz parte o Corpus Concordancia, com entrevistas realizadas entre 2010-2013, no âmbito do Projeto Estudo comparado dos padrões de concordancia em variedades africanas, brasileiras e europeias, um projeto internacional do CLUL, Portugal (Maria Antónia Mota, Investigador Responsável) e UFRJ, Brasil (Sílvia Brandão, Investigador Responsável), iniciado em 2008 e financiado pela CAPES/GRICES. Em 2018, o CSF conta com quase 100 entrevistas e cerca de 60 horas de gravações. 
Assim, a amostra para análise está estratificada em: nivel de escolaridade - seis informantes com o nível 1, analfabetos e falantes com instrução básica, até ao $9^{\circ}$ ano, e seis informantes com nível 2, ou com o Ensino Secundário completo, ou seja, com o $12^{\circ}$ ano de escolaridade; idade - quatro informantes por cada uma das três faixas etárias consideradas, A (18-35 anos), B (36-55 anos) e C (56-75 anos); e sexo ou género - seis informantes do sexo masculino e seis informantes do sexo feminino.

\section{RESULTADOS}

Nesta amostra, foram contabilizados inicialmente, num total de 77 dados, 62 com lhe/ lhes, 13 com SP introduzido por a e apenas dois com SP introduzido por para, de que se fornecem alguns exemplos:

(11) a. mas consegui dar-lhes aquilo que eles queriam (FNC15_HC2)

b. os pais tamém [também] se falam duas três quatro vezes cinco vezes e mais por aí e [...]não dá intimidade a eles (FNC15_MB)

c. a gente já tinha um conhecimento d'alguns [de alguns] palavrões i [e] dizemes [dizemos] pra'ele [para ele] (FNC17_HB2)

Para prosseguir à análise com o Goldvarb, uma vez que inicialmente se obteve knockout devido ao número reduzido de duas ocorrências de SP com para, optou-se por considerar apenas, para além das construções padrão com clítico, as construções com SP introduzidas pela preposição a. Os resultados globais, em termos de percentagens, mostram que a variante padrão, com clítico the, é a mais produzida, com $83 \%$ das ocorrências (Gráfico 1).

Gráfico 1: Realização de OI anafórico de 3P numa variante insular do PE (Funchal)

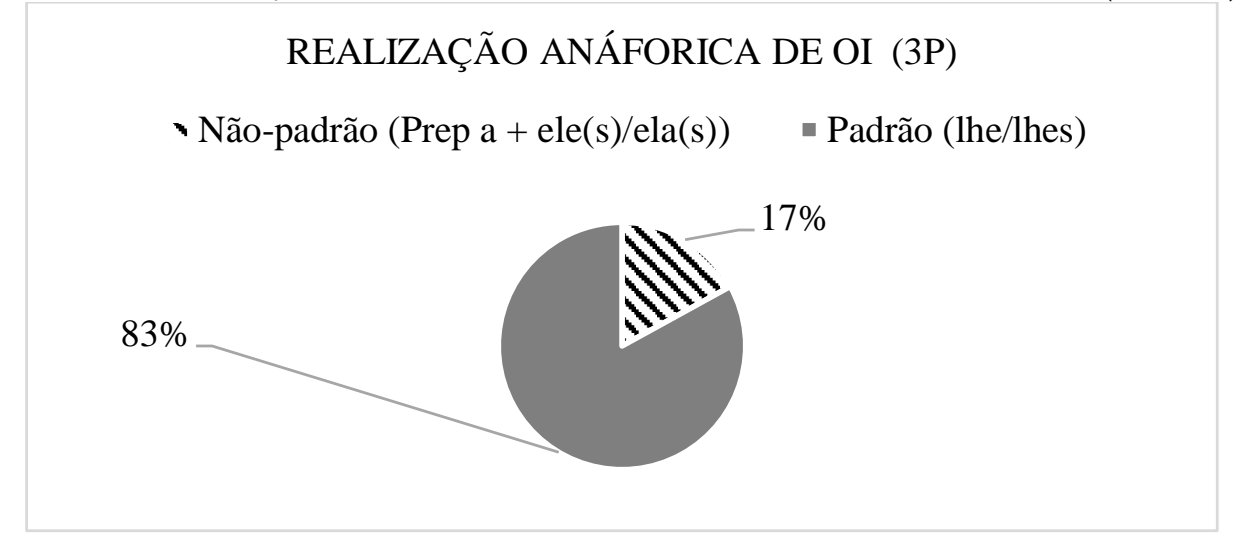

Quando se tem em conta as variáveis sociais, é possível observar algumas tendências de uso. As mulheres são as que mais utilizam a forma padrão (58\%), mas também as que mais produzem as formas inovadoras não-padrão $(12 \%)$, com SP, com a preposição $a+$ pronome forte ele(s), ela (s). 


\section{Revista

Gráfico 2: Realização de OI anafórico de 3P numa variante insular do PE (Funchal): variável género do informante

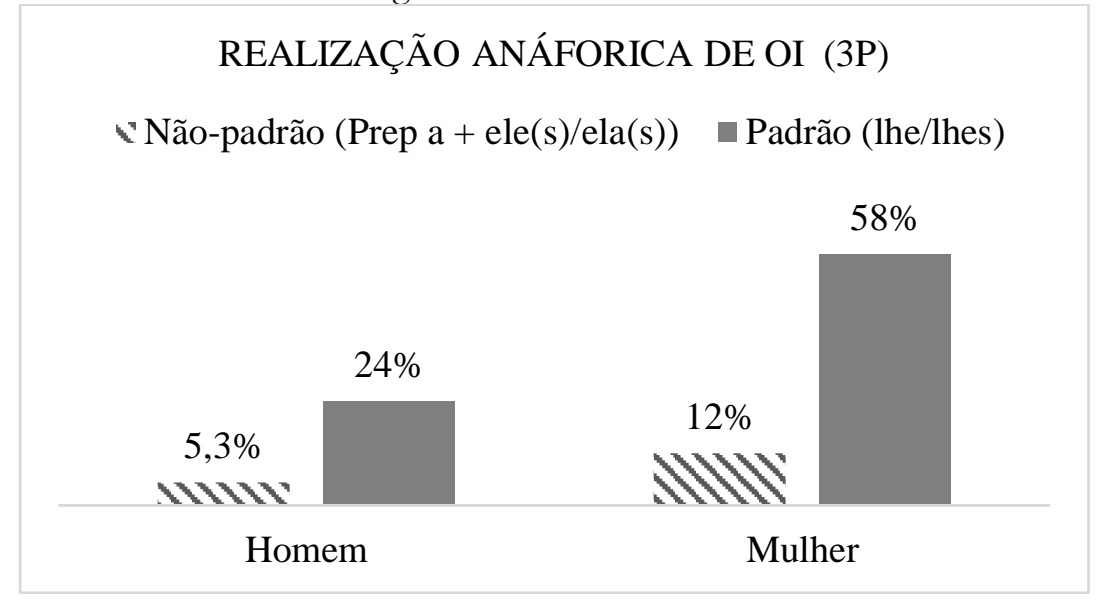

Quando se tem em conta o fator idade do informante, a tendência é para que os jovens não produzam as formas não padrão $(1,4 \%)$, em contraste com informantes mais velhos, não só junto daqueles cuja idade se situa entre os 36 e os 55 anos, responsáveis por $10,6 \%$ das ocorrências, como também daqueles com idade acima dos 55 anos, responsáveis por $5,4 \%$ dos dados (Gráfico 3).

Gráfico 3: Realização de OI anafórico de 3P numa variante insular do PE (Funchal): variável idade do informante

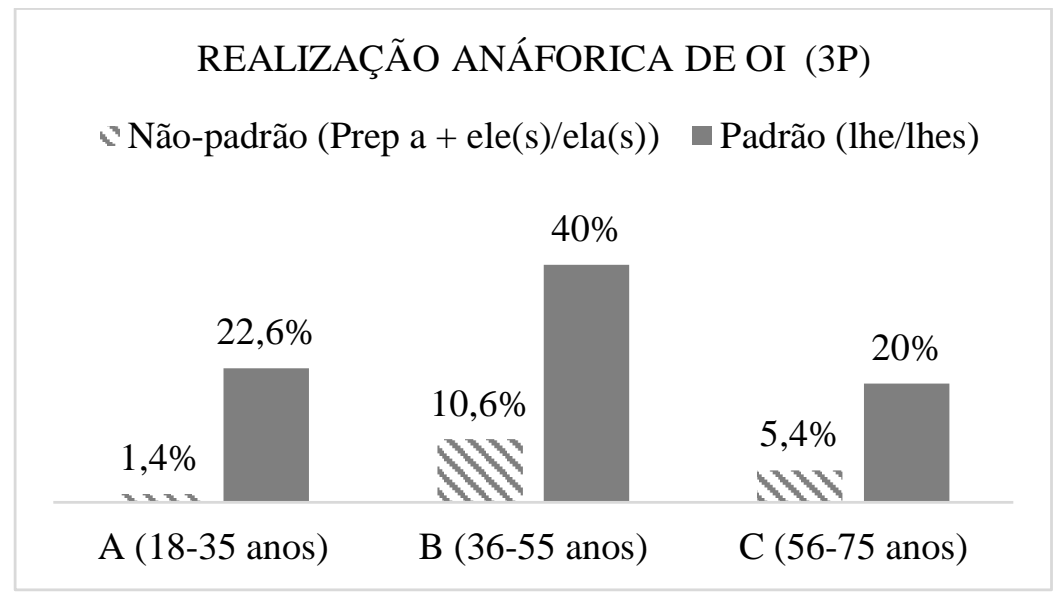

Tal como em outros trabalhos de sociolinguística realizados sobre a comunidade de fala do Funchal, a variável nível de escolaridade configura uma acentuada assimetria na marcação de OI. Os informantes menos escolarizados são aqueles que menos produzem clíticos (5,4\%), preferindo a produção de SP (a) não-padrão (12\%) (Gráfico 4). 


\section{das Letras}

Gráfico 4: Realização de OI anafórico de 3P numa variante insular do PE (Funchal): variável nível de escolaridade do informante

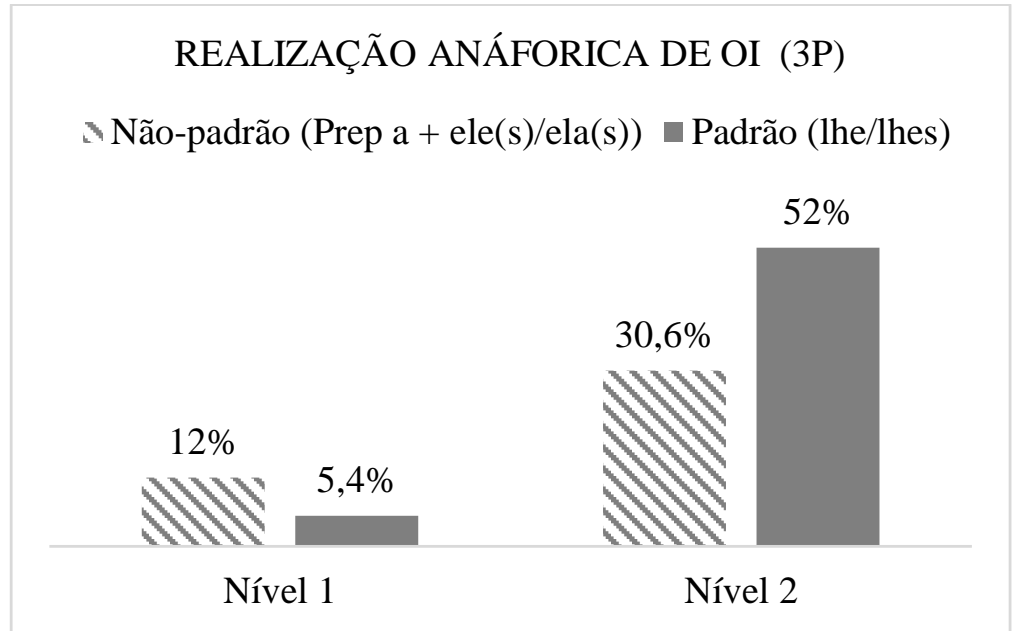

Em (12), a seguir, apresentam-se alguns dados retirados da amostra, a maioria produzida por informantes com nível 1 de escolaridade $(11 \mathrm{a}-\mathrm{d})$.

(12) a. e eu pedi a ela e ela não me ajudou (FNC11_MA1)

b. e eu pedi a ele para me pôr a pedra aqui (FNC10_HC1)

c. foi [fui] eu que paguei a conta a ela (FNC15_MB1)

d. e o estade [Estado] fornece proteção a eles (FNC15-HC1)

e. vão investir esse dinheiro noutro país_vão dar comer a eles (FNC15_MC2)

Apesar de a amostra conter apenas 77 dados, foi possível realizar a análise estatística, ou Binominal, pelo Goldvarb, com significância 0,018. Esta análise apurou dois fatores que condicionam significativamente a variação: o nível de escolaridade dos informantes e a informação morfológica do constituinte OI a que se referem as formas produzidas. Assim, confirma-se que a probabilidade de produzir SP não padrão é maior se o informante for pouco escolarizado, ou de nivel 1 (peso relativo 0,772), e se na forma de realização o pronome tónico estiver no plural (peso relativo 0,752).

\section{CONSIDERAÇÕES FINAIS}

Nesta investigação preliminar, com recurso a uma amostra reduzida, foi possível utilizar o Goldvarb, um software concebido para a análise multivariada de dados sociolinguísticos e extrair alguns padrões de usos. A análise realizada através desta abordagem teórico-metodológica com grande tradição na descrição do $\mathrm{PB}$, mas incipiente quando o foco é o PE, indica estarmos em presença de fenómenos sintáticos específicos, inexistentes em Portugal Continental.

$\mathrm{Na}$ comunidade de fala do Funchal, fica patente a produção de realizações OI não padrão, com SP introduzidas por a e para e seguidas de pronome forte $(e l e(s) /$ ela $(s))$. A 
abordagem utilizada permitiu apurar ainda a influência de fatores sociais na realização variável de OI, uma vez que são os falantes com menores níveis de escolaridade (nível 1), isto é, com pouco contacto com a escola e com a variedade do PE padrão por ela transmitida, quem mais recorre a formas de SP não padrão. Esta situação está em conformidade com outros estudos sobre variação sintática realizados a partir de amostras do CSF (VIEIRA; BAZENGA, 2013; RODRIGUES, 2018; BAZENGA; ANDRADE; RODRIGUES, 2019, por exemplo), que convergem todos para a importância da variável nível de escolaridade na variação sintática observada de determinado fenómeno.

Os dados do Funchal conduzem ainda à possibilidade de postular uma situação dinâmica de processo de convergência linguística das variedades do português em determinados domínios sintáticos, na esteira das hipóteses formulados na literatura sociolinguística europeia (AUER, 2005; BERRUTO, 2010; CERRUTI; REGIS, 2015). O contraste entre variedades (PE e PB) no domínio da realização de OI anafórico de $3^{\mathrm{a} a}$ pessoa fica mais ténue, uma vez que esta variedade insular do PE partilha parcialmente algumas propriedades apontadas como específicas ao PB. A variedade insular do PE funcionaria, assim, como uma variedade intermédia, entre as variedades do PE e do PB, cada uma das três obedecendo a diferentes restrições de escolhas e padrões de usos. A Esta "constelação entre variedades" deverá, no entanto, ser confirmada por uma investigação em grande escala, recorrendo a amostras maiores e mais significativas em termos quantitativos.

No que se refere à análise dos padrões de realização de OI na variedade do português falado no Funchal, para além de um maior volume de dados, seria importante formular outras hipóteses estruturais de realização de OI, a realização nula, por exemplo, que também estaria na origem da aquisição tardia dos clíticos em PE, como referido. Só assim, será possível obter um melhor entendimento da gramática do OI em uso pela comunidade portuguesa insular e as suas eventuais conexões com o sistema de regras a que recorrem os falantes de outras variedades geográficas e sociais do português.

\section{REFERÊNCIAS}

ALMEIDA, Gilce de Souza. Uso dos pronomes-objeto de segunda pessoa na fala de Salvador e de Santo Antônio de Jesus. Veredas, v. 20, nº 2, p. 122-135, 2016.

AUER, Peter. Europe's sociolinguistic unity, or: a typology of European dialect / standard constellations. In: DELBECQUE, N.; AUWERA, J. van der; GEERAERTS, D. (Eds.). Perspectives on variation: sociolinguistics, historical, comparative. Berlin e New York: Mouton de Gruyter, 2005, p. 7-42.

BAZENGA, Aline. A variação entre ter e haver em construções existenciais numa variedade insular do PE (Funchal). In: ATAS IV CILH, no prelo. 
BAZENGA, Aline. Variação e variedades não-dominantes do português: contributo para a configuração de luso-versais (ou universais vernáculos do português. Comunicação apresentada no XIII Congreso Internacional de Linguistica Xeral. Universidad de Vigo, 13-15 de junho de 2018. DOI: 10.13140/RG.2.2.34253.95203.

BAZENGA, Aline; RODRIGUES, Lorena (no prelo). Usos do clítico the em variedades do português. Actas Pelos Mares da Lingua Portuguesa 4, Aveiro, UA Editora, 2018.

BAZENGA, Aline; ANDRADE, Catarina; RODRIGUES, Lorena. Variantes sintáticas (padrão e não-padrão) em Português: representações sociais e atitudes linguísticas de Falantes madeirenses. In: RAZKY, A.; SFAR, I.; SOUTET, O.; MEIRI, S. Variations et Dynamiques Langagières. Actes du IV ème Congrès International de Dialectologie et de Sociolinguistique. Paris, Université Paris Sorbonne, 2019: Disponível em: [http://www.youblisher.com/p/2020945-Variations-et-dynamiques-langagieres/]. Acesso em: 25 fev. 2019.

RODRIGUES, Lorena; BAZENGA, Aline. Variação linguística dos pronomes pessoais de terceira pessoa no português falado no Brasil e na Madeira. Atas do Congresso Internacional em V ariação Linguistica nas Linguas Românicas, Aveiro: UA Editora, no prelo.

BERLINCK, Rosane de A. The Portuguese dative. In: VAN BELLE, W.; VAN LANGENDONCK, W. (Eds.). The dative. Vol 1: Descriptive studies. Amsterdam: John Benjamins, 1996, p. 119-151.

BRISSOS, Fernando; GILLIER, Raissa; SARAMAGO, João. O problema da subdivisão dialetal madeirense: estudo dialetométrico da variação lexical. Revista da Associação Portuguesa de Linguística, n. 2-10, p. 31-47, 2016.

BERRUTO, Gaetano. Identifying dimensions of linguistic variation in a language space. In: AUER, P.; SCHMIDT, J. E. (Eds.). Languages and space: an international handbook of linguistic variation. Vol. 1: Theories and methods. Berlin e New York: Mouton the Gruyter, p. 226-241, 2010.

BRITO, Ana Maria. As construções ditransitivas revisitadas: alternância dativa em Português Europeu? In: Textos Seleccionados, XXIX Encontro nacional da associação portuguesa de linguistica. Porto: APL, 2014, p. 103-119.

BRITO, Ana Maria. Construções de objecto indirecto preposicionais e não preposicionais: uma abordagem generativo-constructivista. In: FIÉIS, A.; COUTINHO, A. (Orgs.) Textos Seleccionados do XXIV Encontro da Associação Portuguesa de Linguística. Lisboa: Colibri, 2009, p. 141-159.

CARMONA, Jacqueline; SILVA, Carolina. A aquisição de clíticos dativos em PE: teste piloto. In: COUTINHO, A. M.; LOBO, M. (Eds.) Textos Seleccionados. XXII Encontro Nacional da APL. APL/Colibri: Lisboa, 2007, p. 199-210.

CERRUTI, Massimo; REGIS, Riccardo. The interplay between dialect and standard. In: TORGERSEN, E.; HARSTAD, S; MAEHLUM, B.; ROYNELAND, U. (Eds). Language 
Variation - European Perspctives V: Selected papers from the Seventh International Conference on Language Variation in Europe (ICLAVE 7). John Benjamins, p. 55-68, 2015.

COSTA, João; LOBO, Maria. Complexidade e omissão de clíticos: o caso dos reflexos. In: XXII Encontro Nacional da Associação Portuguesa de Linguística. Textos Seleccionados, Lisboa: APL, 2007, p. 303-313.

COSTA, João; LOBO, Maria. A aquisição de clíticos em PE: omissão de clíticos ou objecto nulo?. In: XXI Encontro Nacional da Associação Portuguesa de Linguística. Textos Seleccionados. Lisboa: APL, 2006, p. 285-293.

COSTA, João; FIÉIS, Alexandra; LOBO, Maria. A aquisição dos pronomes clíticos no português L1. In: MARTINS, A. M.; CARRILHO, E. (Eds.). Manual de linguística portuguesa. Berlim: Mouton de Gruyter, 2016, p. 431-452.

FIGUEIREDO, Carlos; JORGE, Lurdes; OLIVEIRA, Márcia de. Clítico argumental "lhe" no Português do Libolo: Estrutura formal e Caso (abstracto). In: FIGUEIREDO, C.; OLIVEIRA, M. (Orgs.). "Projeto Libolo" - Municipio do Libolo, Kwanza-Sul, Angola: aspectos linguístico-educacionais, histórico-culturais, antropológicos e sócio-identitários, v. 1. Lisboa: Chiado Editora, 2016, p. 253-264.

FREIRE, Gilson C. A realização do acusativo e do dativo anafóricos de terceira pessoa na escrita brasileira e lusitana. Tese de doutoramento, Universidade Federal do Rio de Janeiro. Rio de Janeiro, 2005.

FREIRE, Gilson C. Acusativo e dativo anafóricos de $3^{\text {a }}$ pessoa na escrita brasileira e lusitana. Revista Abralin, v.10, n. 1, p. 11-32, 2011.

GONÇALVES, Anabela; RAPOSO, Eduardo. Verbo e sintagma nominal. In: RAPOSO, E.; NASCIMENTO, M. F.; MOTA, M. A.; SEGURA, L.; MENDES, A. (Orgs.). Gramática do Português. v. I. Lisboa: Fundação Calouste Gulbenkian, 2013, p. 1155-1218.

GONÇALVES, Perpétua. O português em África. In: RAPOSO, E.; NASCIMENTO, M. F.; MOTA, M. A.; SEGURA, L.; MENDES, A. (Orgs.). Gramática do português. V.1. Lisboa: Fundação Calouste Gulbenkian, 2013, p. 157-178.

GONÇALVES, Rita. Construções ditransitivas no português de São Tomé. Dissertação de Doutoramento. Lisboa: FLUL, 2016.

HAGEMEIJER, Tjerk. O português em contacto em África. In: MARTINS, A. M.; CARRILHO, E. (Eds.). Manual de linguística portuguesa. Berlim: Mouton de Gruyter, 2016, p. 43-67.

LINS, Alex Batista. Três hipóteses e alguns caminhos para melhor compreender o processo constitutivo do português brasileiro. In: OLIVEIRA, K.; CUNHA E SOUZA, H. F.; SOLEDADE, J. (Orgs.). Do português arcaico ao português brasileiro: outras histórias. Salvador: EDUFBA, 2009, p. 271-296.

MADEIRA, A.; CRISPIM; M. de L.; XAVIER, M. F. Clíticos pronominais em português L2. In: OLIVEIRA, F.; BARBOSA, J. (Orgs.). Textos Seleccionados do XXI Encontro da 
Associação Portuguesa de Linguística. Lisboa: Associação Portuguesa de Linguística, p. 495510, 2006.

MARTINS, Ana Maria. Posição dos pronomes pessoais clíticos. RAPOSO, E.; NASCIMENTO, M. F.; MOTA, M. A.; SEGURA, L.; MENDES, A. (Orgs.). Gramática do português. v. II. Lisboa: Fundação Calouste Gulbenkian, p. 2231-2302, 2013.

MATEUS, Maria Helena Mora et al. Gramática da lingua portuguesa. Lisboa: Caminho, 1983.

NARO, Anthony; SCHERRE, Maria Marta. Origens do português brasileiro. São Paulo: Parábola, 2007.

NASCENTES, Antenor. Lheísmo no português do Brasil. Revista Letras, n. 11, p. 108113, 1960.

RODRIGUES, Lorena; BAZENGA, Aline. Variação linguística dos pronomes pessoais de terceira pessoa no português falado no Brasil e na Madeira. Atas do Congresso Internacional em V ariação Linguistica nas Linguas Românicas. Aveiro: UA Editora, no prelo.

RODRIGUES, Lorena. O caso acusativo nos pronomes pessoais de terceira pessoa do português brasileiro e europeu. Dissertação de doutoramento. Universidade Federal do Ceará, Brasil, 2018.

SALLES, Heloísa M. L.; SCHERRE, Martha M. P. Indirect objects in ditransitive constructions in Brazilian Portuguese. In: NÚÑEZ-CEDEÑO, R.; LÓPEZ, L.; CAMERON, R. (Orgs.). A Romance perspective on language knowledge and use. Amsterdam/Philadelphia: John Benjamins, 2003, p. 151-165.

SILVA, Carolina. Assimetrias na aquisição de diferentes tipos de clíticos em português europeu. In: Textos Seleccionados. XXIV Encontro Nacional da Associação Portuguesa de Linguística. Lisboa: APL, 2009, p. 527-541.

TORRES MORAIS, Maria Aparecida; BERLINCK, Rosane de A. A caracterização do objeto indireto no português: aspetos sincrônicos e diacrônico. In: LOBO, T. et al. (Orgs.). Para a bistória do português brasileiro, Tomo I. Bahia: EDUFBA, 2006, p. 73-106.

TORRES MORAIS, Maria Aparecida; BERLINCK, Rosane de A. 'Eu disse pra ele' ou 'Disse-lhe a ele': a expressão do dativo nas variedades brasileira e européia do português. In: CASTILHO, Ataliba T.; TORRES MORAIS, M. A; LOPES, R. E. V.; CYRINO, S. M. L. (Orgs.). Descrição, história e aquisição do português brasileiro - Estudos dedicados a Mary A. Kato. São Paulo: Fapesp. Campinas: Pontes Editores, 2007, p. 61-83.

TORRES MORAIS, Maria Aparecida; SALLES, Heloisa M. M. Parametric change in the grammatical encoding of indirect objects in Brazilian Portuguese. Probus, v. 22, n. 2, p. 181-210, 2010.

TORRES MORAIS, Maria Aparecida. Sentenças bitransitivas e objeto indireto no português brasileiro. Linha D'Água, 25(2), p. 25-50, 2012. Disponível em: [https://doi.org/10.11606/issn.2236-4242.v25i2p25-50]. Acesso em 25 de fev. de 2019. 


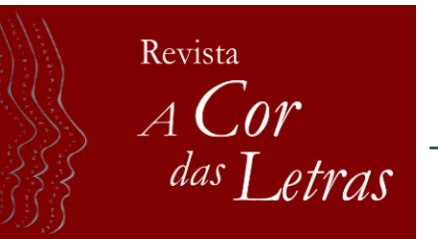

VIEIRA, Silvia Rodrigues; BAZENGA, Aline. Patterns Of third person plural verbal agreement. Journal of Portuguese Linguistics, v. 12(2), p. 7-50, 2013.

Recebido em: 28/02/2019

Aprovado em: 07/06/2019

Publicado em: 28/09/2019 